\title{
HPV-16 in a distinct subset of oral epithelial dysplasia
}

\author{
Mark A Lerman ${ }^{1}$, Soulafa Almazrooa ${ }^{2}$, Neal Lindeman ${ }^{3,4}$, Dimity Hall ${ }^{5}$, Alessandro Villa ${ }^{6,7}$ \\ and Sook-Bin Woo ${ }^{6,7,8}$ \\ ${ }^{1}$ Department of Diagnostic Sciences, Tufts University School of Dental Medicine, Boston, MA, USA; \\ ${ }^{2}$ Department of Diagnostic Sciences, King Abdulaziz University, Jeddah, Saudi Arabia; ${ }^{3}$ Department of \\ Pathology, Harvard Medical School, Boston, MA, USA; ${ }^{4}$ Center for Advanced Molecular Diagnostics, \\ Department of Pathology, Brigham and Women's Hospital, Boston, MA, USA; ${ }^{5}$ Department of Quality Control, \\ Thermo Fisher Scientific, Bedford, MA, USA; ${ }^{6}$ Department of Oral Medicine, Infection, and Immunity, \\ Harvard School of Dental Medicine, Boston, MA, USA; ${ }^{7}$ Division of Oral Medicine and Dentistry, Brigham and \\ Women's Hospital, Boston, MA, USA and ${ }^{8}$ Department of Pathology, StrataDx, Lexington, MA, USA
}

\begin{abstract}
Human papillomavirus (HPV) 16 is the most common high-risk HPV type identified in oropharyngeal and cervical neoplasia. Recently, HPV-associated oral epithelial dysplasia with specific histopathologic features and demographics similar to HPV-oropharyngeal carcinoma has been identified. The objective of this study was to evaluate histopathologically all cases of HPV-oral epithelial dysplasia seen in one center and identify HPV types in a subset of cases. Cases with specific histopathology for HPV-oral epithelial dysplasia that were positive both by immunohistochemical studies for p16 and by in situ hybridization for high-risk types of HPV were further analyzed using QIAamp DNA Tissue Kits (Qiagen, Hilden, Germany). DNA was extracted, amplified, and digested with restriction enzymes and run on a polyacrylamide gel. Digestion patterns were visually compared with a database of known HPV digestion patterns for identification. There were 53 specimens included in the analysis. There were 47 males and six females (7.8:1), with a median age of 55 years (range 41-81). The most common site of involvement was the tongue/floor of mouth ( $77 \%$ of cases). Of the 53 cases, $94 \%$ exhibited parakeratosis and/ or hyperkeratosis. All the cases featured karyorrhexis, apoptosis, and characteristics of conventional carcinoma in situ. The quantity of DNA extracted was sufficient for analysis in 22 cases. HPV-16 was identified in 20/22 (91\%) cases. One case was associated with HPV-33 and one with HPV-58 (5\% each). Eight of the 53 cases (15\%) were associated with invasive squamous cell carcinomas.

Modern Pathology (2017) 30, 1646-1654; doi:10.1038/modpathol.2017.71; published online 4 August 2017
\end{abstract}

Human papillomavirus (HPV) infection has been well established as a cause of anal and genital tract cancers and, more recently, oropharyngeal cancers. ${ }^{1-6}$ HPV-16 is the most common high-risk HPV type identifed, accounting for at least $50 \%$ of cervical squamous cell carcinomas. ${ }^{2,7}$ HPV-16 has been identified in over $90 \%$ of oropharyngeal squamous cell carcinomas, with HPV types HPV-18, -33 , and -52 less frequently identified in oral and oropharyngeal squamous cell carcinomas. ${ }^{8-13}$ Studies have shown an improved prognosis for HPVassociated head and neck squamous cell carcinomas

Correspondence: Dr MA Lerman, DMD, Department of Diagnostic Sciences, Tufts University School of Dental Medicine, 1 Kneeland Street, Boston, MA 02111, USA.

E-mail: mark.lerman@tufts.edu

Received 23 December 2016; revised 20 May 2017; accepted 20 May 2017; published online 4 August 2017 compared with HPV-negative cancers. ${ }^{14,15}$ The prevalence of HPV in oral cavity squamous cell carcinomas is $4-6 \%$ and there have been very few studies that evaluated the prevalence of HPV in oral epithelial dysplasia. ${ }^{8,16-20}$

In 2013, we reported high-grade oral epithelial dysplasia that exhibited distinctive histopathologic features of dysplasia that predicted positivity both for p16 and for high-risk types of HPV by DNA in situ hybridization in $100 \%$ of cases. ${ }^{21}$ The objective of the current study is to identify specific HPV types associated with this distinctive form of HPV-oral epithelial dysplasia.

\section{Materials and methods}

Cases of HPV-oral epithelial dysplasia were identified from September 2008 to August 2016 from the 
archives of StrataDx, a surgical pathology laboratory in Lexington, MA, USA affiliated with the Harvard School of Dental Medicine. All the cases were reviewed by two oral and maxillofacial pathologists (SBW and MAL). Only cases that demonstrated the specific histopathologic features for HPV-oral epithelial dysplasia that had been described in a previous study and with immunohistochemical studies for p16 that were positive in a contiuous band through the full thickness of the epithelium were considered for inclusion. ${ }^{21}$

Regions of interest were macro-dissected from 5micron sections of formalin-fixed paraffin-embedded tissue and DNA was isolated using QIAamp Mini kit (Qiagen, Hilken, Germany) following manufacturer's instructions. HPV genotyping was done by a polymerase chain reaction-restriction fragment length polymorphism (PCR-restriction fragment length polymorphism) method. Briefly, a PCR reaction was first performed using HPV consensus primers designed to amplify a conserved $332-470 \mathrm{bp}$ fragment of the HPV L1 gene, and the PCR products were analyzed on a $5 \%$ polyacrylamide gel stained with ethidium bromide. If a visible product was present, the PCR product was digested with three different restriction enzymes, Pst I, Rsa I, and Hae III (New England Biolabs), following the manufacturer's directions. The digested products were visualized on a $5 \%$ polyacrylamide gel stained with ethidium bromide and the patterns of the digested products compared with a database of known patterns to determine the genotype (Figure 1). A control PCR reaction with primers to a $500 \mathrm{bp}$ fragment of the human beta-globin was also performed to assess the quality of the DNA.

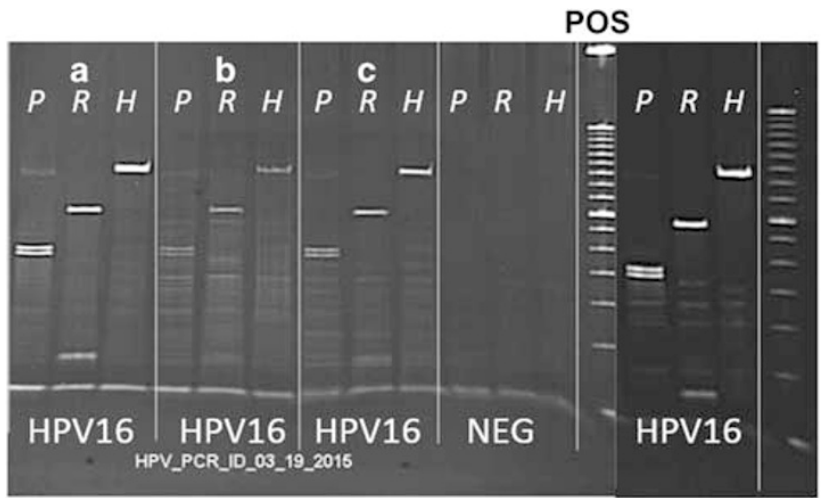

Figure 1 Molecular diagnostic test results for HPV. Each sample (labeled 1, 2, 3, NEG: negative control, POS: positive control for HPV-16) is amplified by PCR with primers to a portion of the HPV L1 major capsid protein gene, digested with one of three restriction enzymes (Pst I, Rsa I, HaeI), and separated by polyacrylamide (5\%) gel electrophoresis. The pattern of fragments is matched to a library of fragments derived from different HPV genotypes to arrive at a designation for each sample. The patterns for specimens, a, b, and c each match to HPV-16. H: Hael; P: Pst l; R: Rsa I.

\section{Results}

There were 53 cases included in the analysis, of which the histopathology for 19 had been previously reported (Table 1). ${ }^{21}$ The median age was 55 years (range 41-81) and there were 47 males (M:F ratio $=$ 7.8:1). Of the 45 lesions accompanied by a clinical description, $28(62 \%)$ were reported as white,

Table 1 Clinical data and HPV type

\begin{tabular}{|c|c|c|c|c|}
\hline Case & Age & Gender & Location & HPV type \\
\hline 1 & 51 & M & Tongue/floor of mouth & NAD \\
\hline 2 & 60 & $\mathrm{M}$ & Lateral tongue & 16 \\
\hline 3 & 43 & $\mathrm{M}$ & Tongue & NAD \\
\hline 4 & 45 & $\mathrm{~F}$ & Ventral tongue & NAD \\
\hline $5^{\mathrm{a}}$ & 70 & M & Ventral tongue & NAD \\
\hline 6 & 41 & $\mathrm{M}$ & Ventral tongue & NAD \\
\hline 7 & 56 & $\mathrm{M}$ & Buccal mucosa & 16 \\
\hline 8 & 69 & $\mathrm{M}$ & Floor of mouth & 16 \\
\hline 9 & 62 & M & Buccal mucosa & NAD \\
\hline 10 & 48 & $\mathrm{M}$ & Ventral tongue & NAD \\
\hline 11 & 56 & $\mathrm{M}$ & Ventral tongue & 16 \\
\hline 12 & 46 & $\mathrm{M}$ & Anterior tongue & 16 \\
\hline $13^{\mathrm{a}}$ & 62 & $\mathrm{M}$ & Tongue & NAD \\
\hline 14 & 55 & $\mathrm{~F}$ & Gingiva & 16 \\
\hline $15^{\mathrm{a}}$ & 55 & $\mathrm{~F}$ & Gingiva & 16 \\
\hline 16 & 71 & $\mathrm{M}$ & Ventral tongue & 16 \\
\hline 17 & 54 & $\mathrm{M}$ & Floor of mouth & 16 \\
\hline 18 & 61 & $\mathrm{M}$ & Floor of mouth & 16 \\
\hline 19 & 67 & $\mathrm{M}$ & Ventral tongue & 16 \\
\hline $20^{\mathrm{a}}$ & 72 & M & Ventral tongue & 33 \\
\hline 21 & 61 & $\mathrm{M}$ & Ventral tongue & 58 \\
\hline 22 & 51 & M & Ventral tongue & 16 \\
\hline 23 & 49 & $\mathrm{~F}$ & Ventral tongue & 16 \\
\hline 24 & 55 & $\mathrm{~F}$ & Buccal mucosa & 16 \\
\hline 25 & 57 & M & Ventral tongue/floor of mouth & NAD \\
\hline 26 & 46 & M & Retromolar pad & NAD \\
\hline 27 & 59 & M & Ventral tongue & 16 \\
\hline 28 & 51 & $\mathrm{M}$ & Lateral tongue & 16 \\
\hline 29 & 57 & $\mathrm{M}$ & Floor of mouth & 16 \\
\hline 30 & 57 & $\mathrm{M}$ & Floor of mouth & 16 \\
\hline 31 & 49 & $\mathrm{M}$ & Ventral tongue & 16 \\
\hline 32 & 47 & M & Buccal mucosa & 16 \\
\hline 33 & 55 & $\mathrm{M}$ & Labial mucosa & NAD \\
\hline 34 & 64 & $\mathrm{M}$ & Lateral tongue & NAD \\
\hline 35 & 52 & M & Lip & NAD \\
\hline 36 & 54 & M & Floor of mouth & NAD \\
\hline 37 & 67 & M & Lateral tongue & NAD \\
\hline $38^{\mathrm{a}}$ & 66 & $\mathrm{~F}$ & Tongue & NAD \\
\hline $39^{b}$ & 61 & $\mathrm{M}$ & Tongue & NAD \\
\hline $40^{\mathrm{a}, \mathrm{b}}$ & 50 & $\mathrm{M}$ & Buccal mucosa & NAD \\
\hline $41^{\mathrm{a}}$ & 49 & M & Floor of mouth & NAD \\
\hline $42^{\mathrm{a}}$ & 58 & $\mathrm{M}$ & Soft palate & NAD \\
\hline 43 & 62 & $\mathrm{M}$ & Ventral tongue & NAD \\
\hline 44 & 64 & M & Lingual frenum & NAD \\
\hline 45 & 55 & $\mathrm{M}$ & Soft palate & NAD \\
\hline 46 & 60 & M & Floor of mouth & NAD \\
\hline 47 & 81 & M & Ventral tongue & NAD \\
\hline 48 & 50 & M & Ventral tongue & NAD \\
\hline $49^{b}$ & 60 & M & Ventral tongue/floor of mouth & NAD \\
\hline $50^{\mathrm{b}}$ & 52 & M & Lateral tongue & NAD \\
\hline 51 & 50 & $\mathrm{M}$ & Floor of mouth & NAD \\
\hline $52^{\mathrm{b}}$ & 46 & M & Ventral tongue & NAD \\
\hline 53 & 43 & $\mathrm{M}$ & Ventral tongue & NAD \\
\hline
\end{tabular}

Abbreviation: NAD, no amplification of DNA.

${ }^{a}$ Dysplasia associated with invasive squamous cell carcinoma.

${ }^{\mathrm{b}}$ In situ hybridization studies negative or equivocal for high-risk human papillomavirus. 


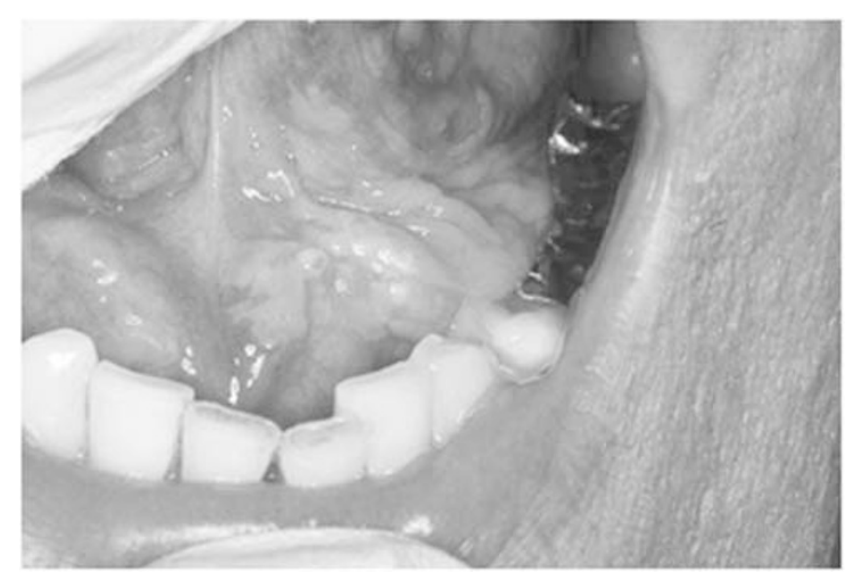

Figure 2 Demarcated leukoplakia of the left floor of mouth.

leukoplakia, or hyperkeratosis, three as red or erythroplakia $(7 \%)$, and three $(7 \%)$ as both red and white or erythro-leukoplakia (Figure 2). Of the 53 lesions, $28(53 \%)$ were located on the tongue, 9 $(17 \%)$ on the floor of mouth, and $3(6 \%)$ involved both sites; one case was on the lingual frenum. As such, 41 cases $(77 \%)$ involved the tongue and/or floor of mouth and lingual frenum (Table 1).

Fifty (94\%) exhibited either parakeratosis and/or hyperkeratosis. Of the 53 cases, $68 \%$ were parakeratinized only, exhibiting brightly eosinophilic parakeratin (Figure 3a). Nine cases (17\%) demonstrated hyperkeratosis only, and five cases (9\%) featured both parakeratosis and hyperkeratosis.

All cases showed karyorrhexis and apoptosis throughout the hyperplastic stratified squamous epithelium with a continuum of changes (Figures 3a, Figures $4 \mathrm{a}$ and $\mathrm{b}$ ). There were cells with karyorrhexis and dense chromatin resembling mitotic figures, similar to the characteristic cells of Heck disease. ${ }^{22}$ Other cells were apoptotic and contained pyknotic nuclei with brightly eosinophilic cytoplasm and a halo from loss of attachment to the adjacent keratinocytes, and finally, nuclei are lost altogether (Figures 3b and 4c). These characteristic findings distinguish these cases from conventional oral epithelial dysplasia. The surrounding cells are generally hyperchromatic and basaloid with increased nucleus:cytoplasm ratio involving the full thickness of the epithelium in all the cases.

All the cases showed strong p16 positivity in a continuous band through the full thickness of the epithelium, excluding the keratin layer (Figures 3c and 4d). In situ hybridization was positive for highrisk types of HPV in 48/53 cases (91\%; Figure 3d). Eight of 53 cases (15\%) were associated with invasive squamous cell carcinomas and these carcinomas developed on the tongue/floor of mouth (5 cases), gingiva, buccal mucosa, and soft palate. Five of the eight carcinomas (63\%) were nonkeratinizing/basaloid and three were minimally keratinizing (38\%; Figure 5).
The quantity of DNA extracted was sufficient for analysis in 22 cases. The following results pertain to this subgroup of patients and there was no statistically significant difference between this subset and the group that was not analyzed in terms of gender, age, or anatomic site (Table 2). The most common site of involvement (12) was the tongue; 5 cases $(23 \%)$ presented on the floor of mouth, 3 cases (14\%) presented on the buccal mucosa, and 2 cases (9\%) were present on the gingiva. HPV-16 was identified in $20 / 22(91 \%)$ cases. Of these, half were from the tongue, $25 \%$ from the floor of mouth, $15 \%$ from the buccal mucosa, and $10 \%$ from the gingiva. One case each was associated with HPV-33 and and HPV-58 ( $5 \%$ each); these two patients were both male, aged 72 and 61, respectively, and both specimens were from the ventral tongue. Of the cases associated with invasive squamous cell carcinomas, two underwent DNA analysis; one each harbored HPV-16 and HPV-33, similar to the overlying oral epithelial dysplasia.

\section{Discussion}

The prevalence of HPV within the oral cavity ranges from 0.9 to $12.0 \%,{ }^{12,23,24}$ with the prevalence of high-risk types reported to be between 1 and $3 \% .{ }^{17,25}$ HPV has also been detected in the oral cavity of children younger than age 20 with a prevalence of 1.9 to $6.0 \% .^{23,26}$ However, most incident and prevalent HPV infections in the mouth are cleared within 1 to 2 years and high viral load predicts persistence of infection. ${ }^{27-29}$

In the United States, the prevalence of HPV in oropharyngeal squamous cell carcinoma has increased significantly over the last several decades. The prevalence was reported at $16.3 \%$ in the $1980 \mathrm{~s}$ and the prevalence has increased to $72.2 \%$ by 2009. ${ }^{30,31} \mathrm{HPV}$ is the cause of squamous cell carcinoma in $70 \%$ of oropharyngeal carcinomas and approximately $85.0 \%$ of the base of tongue and tonsillar squamous cell carcinomas. ${ }^{30,32,33}$ In 2012, Isayeva et $\mathrm{al}^{34}$ reported that the prevalence of HPV detected by PCR in 4195 squamous cell carcinomas of the oral cavity was $20.2 \%$, with the most common type being HPV 16. However, in contrast to the oropharynx, E6/E7 mRNA expression is limited and less than $5 \%$ of oral cavity squamous cell carcinomas appear related to HPV. ${ }^{35,36}$ In a meta-analysis performed in 2011, Jayaprakash et al ${ }^{16}$ reported that HPV is associated with oral epithelial dysplasia in $25.3 \%$ of cases; however, it should be noted that diverse methods of HPV detection were used in the studies included and sensitivity therefore may have varied with PCR showing the significantly higher sensitivity than in situ hybridization. HPV has been detected in squamous cell carcinoma in only 4.0 to $6.0 \%$ of cases by identification of high-risk HPV E6/ E7. ${ }^{18,19}$ Most oropharyngeal squamous cell carcinomas $(>85 \%)$ are caused by HPV-16, with other HPV 

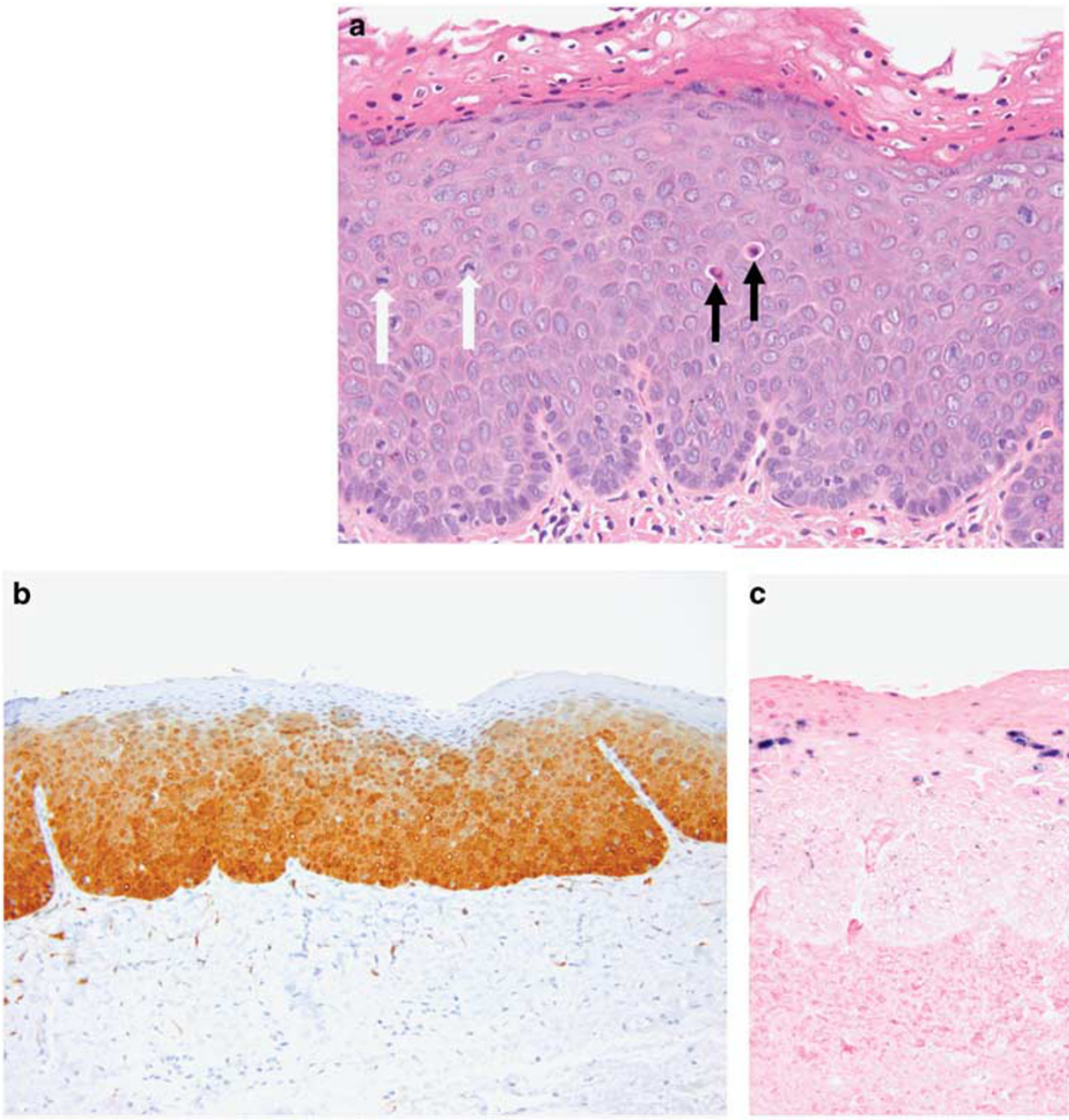

C

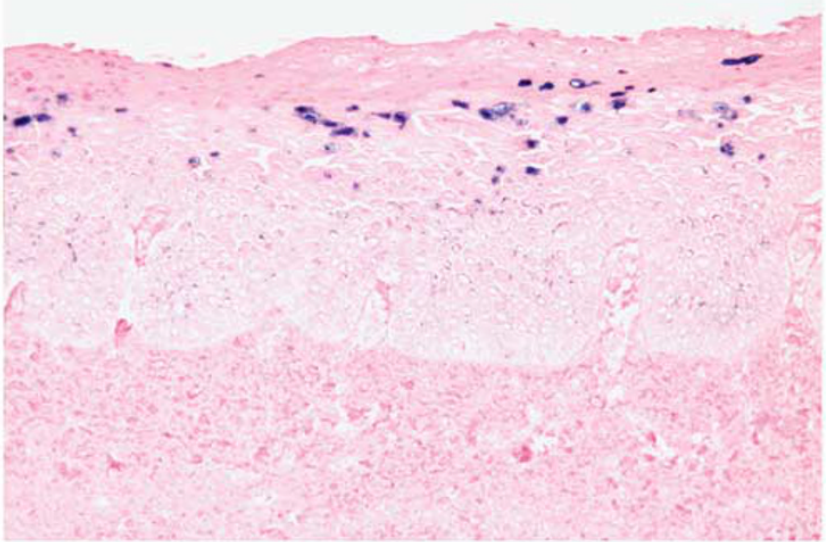

Figure 3 (a) Karyorrhectic cells (white arrows) and apoptotic cells (black arrows) noted throughout the lesion (hematoxylin and eosin, maginification $\times 400$ ). (b) Study for p16 exhibits a continuous band of positivity within the cytoplasm and nuclei of the epithelium, short of the keratin layer (immunohistochemical study for p16, magnification $\times 200$ ). (c) Corresponding study exhibits nuclear positivity for high-risk human papillomavirus (in situ hybridization study for high-risk HPV, magnification × 200).

types such as HPV-18, -33, and -52 identified less frequently. ${ }^{13,30}$ In the cervix, HPV-18, $-33,-45$, and -58 are the most common HPV types implicated in cervical cancer after HPV-16. ${ }^{5,37}$ In this study of oral epithelial dysplasia, HPV-16 was detected by restriction fragment length polymorphism in $91 \%$ of cases while HPV-33 and -58 were each detected in one case each.

There have been a few investigations that evaluated the relationship between HPV and oral epithelial dysplasia confirmed by both p16 and DNA in situ hybridization studies. Two studies reported that $14.6 \%^{38}$ and $35.7 \%^{39}$ of cases of oral epithelial dysplasia were positive for p16 and high-risk HPV by PCR, and $17.5 \%$ of cases were positive for highrisk HPV by DNA in situ hybridization. ${ }^{40}$ Those studies did not specify whether the oral epithelial dysplasias that were positive for HPV had different histopathologic features from those that were not positive. However, a recent study showed that oral epithelial dysplasia that had specific histopathologic features (namely, high numbers of apoptotic and karyorrhectic cells) were positive for p16 and highrisk HPV by DNA in situ hybridization in $100 \%$ of cases. ${ }^{21}$ Similar histopathologic features have been reported previously in oral warts/condylomas without dysplasia and have been referred to as oral bowenoid lesions or virus-associated dysplasia/ bowenoid papulosis. ${ }^{41,42}$ Although five cases (9\%) in the current series were negative or equivocal for HPV by DNA in situ hybridization, this test is not highly sensitive and these results may represent false negatives.

In oropharyngeal cancer, the precursor dysplastic mucosal lesion has not been identified although it is assumed that one is present. In the tonsil, dysplastic precursor lesions within the tonsillar crypt epithelium are difficult to identify because of the complex, invaginated, and tortuous nature of tonsillar crypt epithelium. It is likely that invasive squamous cell carcinoma overgrows the precursor lesion in most cases. On the other hand, the oral cavity is amenable to direct visual examination and most oral squamous cell carcinomas arise from dysplastic precursor 

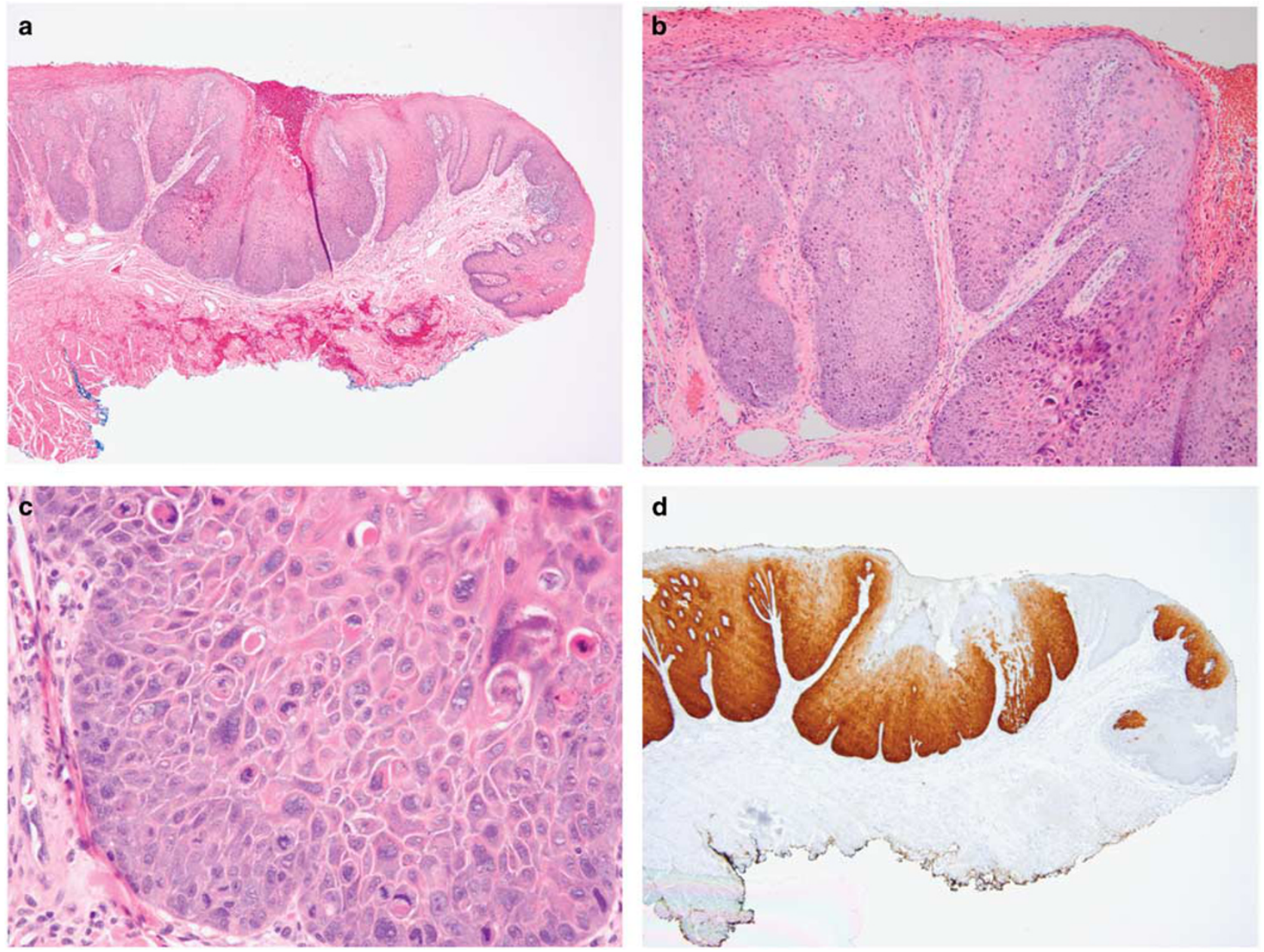

Figure 4 (a) Dysplastic tissue exhibiting parakeratosis and epithelial hyperplasia (hematoxylin and eosin, maginification $\times 40$ ). (b) Numerous karyorrhectic cells and features of conventional epithelial dysplasia throughout the tissue (hematoxylin and eosin, magnification $\times 100$ ). (c) Karyorrhectic cells and apoptotic cells within the bulbous rete ridge of a dysplastic lesion (hematoxylin and eosin, magnification $\times 400$ ). (d) Corresponding study for p16 exhibits a continuous band of positivity within the 'skip' lesions of the dysplastic epithelium (immunohistochemical study for p16, magnification $\times 40$ ).

lesions, the most common of which are leukoplakias and variants such as erythro-leukoplakia. ${ }^{43} \mathrm{HPV}$-oral epithelial dysplasia is no different and presents as leukoplakia occurring at oral sites associated with conventional smoking-related leukoplakia and squamous cell carcinoma, such as tongue and floor of mouth, which constituted $77 \%$ of the cases in this series (Figure 2). Eight out of 53 cases (15\%) in this series showed invasive squamous cell carcinoma and it is therefore likely that such HPV-oral epithelial dysplasias represent the precursor lesions of HPV-associated oral squamous cell carcinoma. There was a stronger male predilection (7.8:1) compared with the 4:1 ratio of HPV-associated oropharyngeal squamous cell carcinoma, and there was a median age of 55 years, younger than patients with smoking-related cancers, but comparable to the median age of 54 for patients with HPV+ oropharyngeal squamous cell carcinoma. ${ }^{29,44,45}$

One case excluded from this study that exhibited the characteristic features of HPV-oral epithelial dysplasia with high-risk HPV identified by DNA in situ hybridization, but was negative for $\mathrm{p} 16$ (Figure 6). Oropharyngeal carcinomas have been described previously that have been positive for HPV but are p16-negative (HPV+p16 - ). ${ }^{46,47}$ It has been suggested that such tumors, which have high recurrence rates and molecular profiles closer to HPV-negative carcinomas than to HPV+p16+ carcinomas, may represent HPV opportunistic infection of pre-existing neoplasms. ${ }^{48}$ At this time, too few HPV+p16 - carcinomas have been identified in the oral cavity to determine their significance.

Many studies have demonstrated improved survival associated with HPV-positive oropharyngeal carcinomas compared with non-HPV-positive tumors. ${ }^{49-52}$ One recent study showed that HPV-16 is associated with lower disease-free survival than other high-risk HPV types. ${ }^{53}$ At this time, there are too few cases of HPV-associated oral cavity squamous cell carcinomas to determine whether 

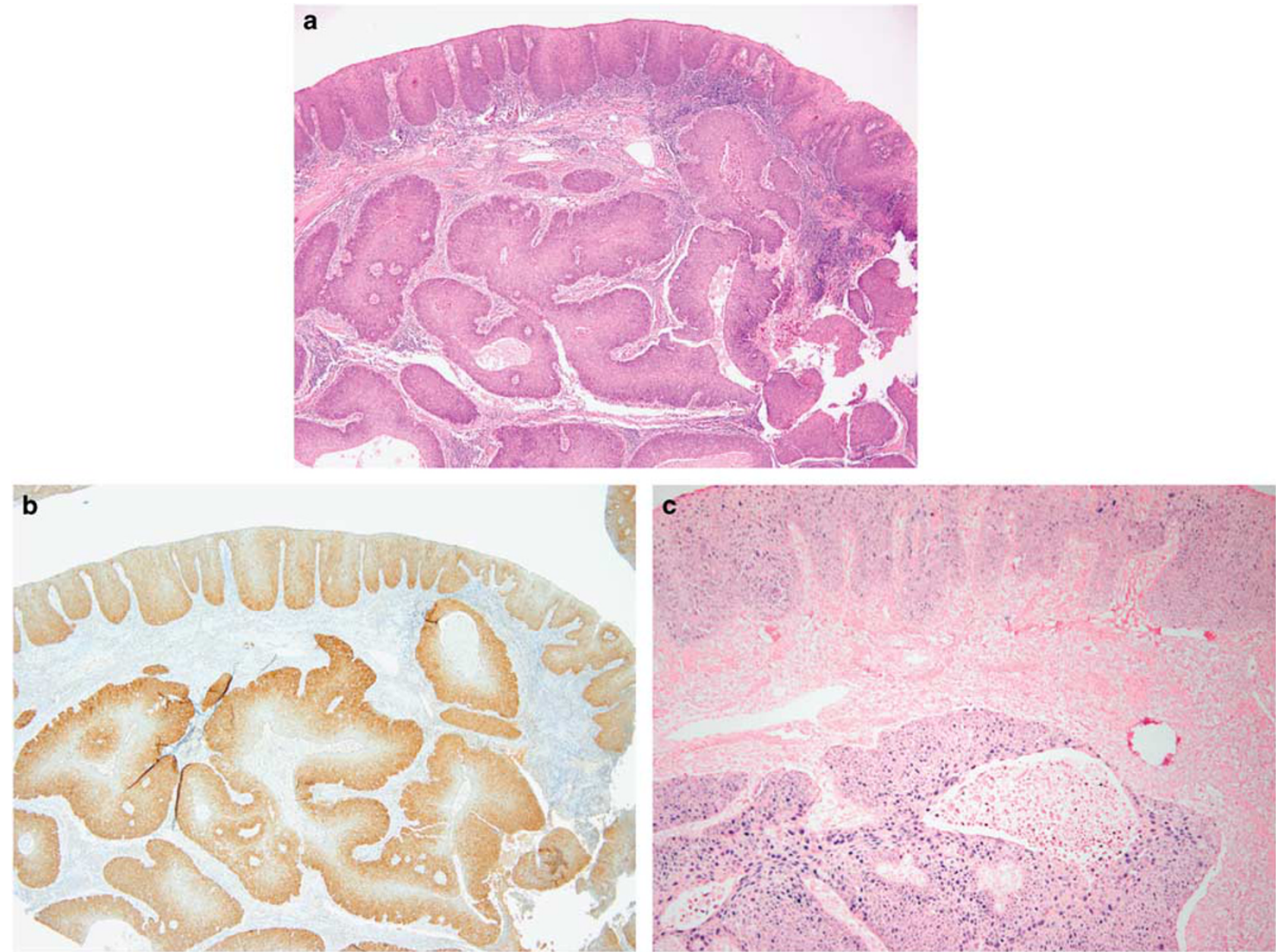

Figure 5 (a) HPV-oral epithelial dysplasia overlying invasive squamous cell carcinoma (hematoxylin and eosin, maginification $\times 40$ ). (b) Corresponding study for p16 exhibits a continuous band of positivity within the invasive tumor islands and within the surface epithelium (immunohistochemical study for p16, magnification $\times 40$ ). (c) Corresponding study exhibits nuclear positivity for high-risk human papillomavirus (in situ hybridization study for high-risk HPV, magnification $\times 100$ ).

Table 2 Comparison of patients with oral epithelial dysplasia with and without HPV genotyping

\begin{tabular}{lccc}
\hline & $\begin{array}{c}\text { Patients with no } \\
\text { HPV typing } \\
(\mathrm{n}=31)(\%)\end{array}$ & $\begin{array}{c}\text { Patients with } \\
\text { HPV typing } \\
(\mathrm{n}=22)(\%)\end{array}$ & P-value \\
\hline Median age & 55.0 & 56.0 & 0.39 \\
Gender & & & \\
Males & $29(94)$ & $18(82)$ & 0.18 \\
Females & $2(7)$ & $4(18)$ & \\
Anatomic site & & & \\
Tongue and/or & $24(77)$ & $17(77)$ & 0.36 \\
floor of mouth & $2(7)$ & $3(14)$ & \\
Buccal mucosa & $2(7)$ & $0(0)$ & \\
Soft palate & $1(3)$ & $2(9)$ & \\
Gingiva & $2(7)$ & $0(0)$ & \\
Lip/labial mucosa & & & \\
\hline
\end{tabular}

they too behave in a less aggressive manner than conventional squamous cell carcinomas. Although a recent retrospective study did not show a statistically significant difference in the survival of patients whose non-oropharyngeal tumors were p16-positive compared with those who were p16-negative, another recent review suggested that patients with p16-positive tumors did have a better prognosis. ${ }^{54,55}$

\section{Conclusion}

HPV-associated oral epithelial dysplasias present as leukoplakias in the oral cavity, similar to nonHPV leukoplakias associated with smoking. However, HPV-associated oral epithelial dysplasias have distinct histopathologic features namely prominent karyorrhexis and apoptosis, and all show strong positivity for p16, similar to oropharyngeal HPV-associated squamous cell carcinomas. As with other cancers, HPV-16 was the most common type identified (91\% of cases) followed by HPV-33 and HPV-58 (4\% each). In this series of cases, HPVoral epithelial dysplasia was associated with invasive squamous cell carcinoma in $8 / 53(15 \%)$ cases and it is unclear whether the prognosis of these squamous cell carcinomas will be different from 

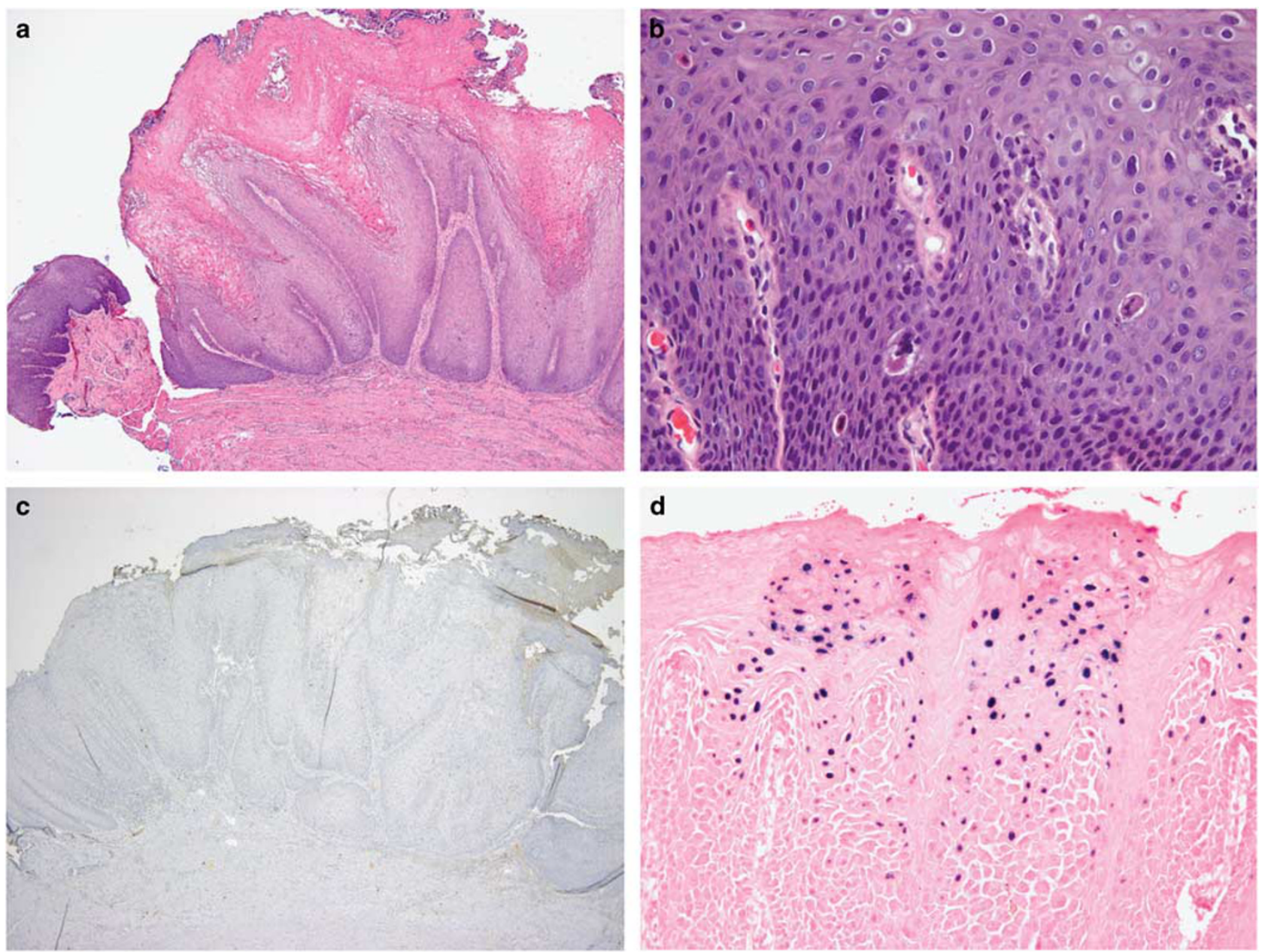

Figure 6 (a) Thick layer of parakeratin overlying dysplastic surface epithelium (hematoxylin and eosin, maginification $\times 40$ ) (b) Characteristic features of HPV-oral epithelial dysplasia, including karyorrhectic cells and apoptotic cells (hematoxylin and eosin, magnification $\times 400$ ). (c) Immunohistochemical studies for p16 are negative (immunohistochemical study for p16, magnification $\times 40)$. $(\mathbf{d})$ Corresponding study exhibits nuclear positivity for high-risk human papillomavirus (in situ hybridization study for high-risk HPV, magnification $\times 200)$.

non-HPV-associated squamous cell carcinomas. Further studies may offer additional information on this entity in the future.

\section{Disclosure/conflict of interest}

The authors declare no conflict of interest.

\section{References}

1 Tilston P. Anal human papillomavirus and anal cancer. J Clin Pathol 1997;50:625-634.

2 Walboomers JM, Jacobs MV, Manos MM, et al. Human papillomavirus is a necessary cause of invasive cervical cancer worldwide. J Pathol 1999;189:12-19.

3 D'Souza G, Kreimer AR, Viscidi R, et al. Case-control study of human papillomavirus and oropharyngeal cancer. N Engl J Med 2007;356:1944-1956.

4 Westra WH. The changing face of head and neck cancer in the 21st century: the impact of HPV on the epidemiology and pathology of oral cancer. Head Neck Pathol 2009;3:78-81.

5 Guan P, Clifford GM, Franceschi S. Human papillomavirus types in glandular lesions of the cervix: a meta-analysis of published studies. Int J Cancer 2013;132:248-250.

6 Gillison ML, Chaturvedi AK, Anderson WF, et al. Epidemiology of human papillomavirus-positive head and neck squamous cell carcinoma. J Clin Oncol 2015;33:3235-3242.

7 Quint KD, de Koning MN, van Doorn LJ, et al. HPV genotyping and HPV16 variant analysis in glandular and squamous neoplastic lesions of the uterine cervix. Gynecol Oncol 2010;117:297-301.

8 Kreimer AR, Clifford GM, Boyle P, et al. Human papillomavirus types in head and neck squamous cell carcinomas worldwide: a systematic review. Cancer Epidemiol Biomarkers Prev 2005;14:467-475.

9 Termine N, Panzarella V, Falaschini S et al. HPV in oral squamous cell carcinoma vs head and neck squamous cell carcinoma biopsies: a meta-analysis (1988-2007). Ann Oncol 2008;19:1681-1690.

10 Singhi AD, Westra WH. Comparison of human papillomavirus in situ hybridization and p16 
immunohistochemistry in the detection of human papillomavirus-associated head and neck cancer based on a prospective clinical experience. Cancer 2010;116: 2166-2173.

11 Anantharaman D, Gheit T, Waterboer T, et al. Human papillomavirus infections and upper aero-digestive tract cancers: the ARCAGE study. J Natl Cancer Inst 2013;105:536-545.

12 D'Souza G, Kluz N, Wentz A, et al. Oral human papillomavirus (HPV) infection among unvaccinated high-risk young adults. Cancers (Basel) 2014;6:1691-1704.

13 Michaud DS, Langevin SM, Eliot M, et al. High-risk HPV types and head and neck cancer. Int J Cancer 2014;135:1653-1661.

14 Ang KK, Harris J, Wheeler R, et al. Human papillomavirus and survival of patients with oropharyngeal cancer. N Engl J Med 2010;363:24-35.

15 Chung CH, Bagheri A, D'Souza G. Epidemiology of oral human papillomavirus infection. Oral Oncol 2014;50: 364-369.

16 Jayaprakash V, Reid M, Hatton E, et al. Human papillomavirus types 16 and 18 in epithelial dysplasia of oral cavity and oropharynx: a meta-analysis, 19852010. Oral Oncol 2011;47:1048-1054.

17 Gillison ML, Broutian T, Pickard RK, et al. Prevalence of oral HPV infection in the United States, 2009-2010. JAMA 2012;307:693-703.

18 Lingen MW, Xiao W, Schmidt A, et al. Low etiologic fraction for high-risk human papillomavirus in oral cavity squamous cell carcinomas. Oral Oncol 2012;49:1-8.

19 Upile NS, Shaw RJ, Jones TM, et al. Squamous cell carcinoma of the head and neck outside the oropharynx is rarely human papillomavirus related. Laryngoscope 2014;124:2739-2744.

20 Ndiaye C, Mena M, Alemany L. Correction to Lancet Oncol 2014; 15: 1324. HPV DNA, E6/E7 mRNA, and p16INK4a detection in head and neck cancers: a systematic review and meta-analysis. Lancet Oncol 2015;16:e262.

21 Woo SB, Cashman EC, Lerman MA. Human papillomavirus-associated oral intraepithelial neoplasia. Mod Pathol 2013;26:1288-1297.

22 Gonzalez LV, Gaviria AM, Sanclemente G, et al. Clinical, histopathological and virological findings in patients with focal epithelial hyperplasia from Colombia. Int J Dermatol 2005;44:274-279.

23 Smith EM, Swarnavel S, Ritchie JM, et al. Prevalence of human papillomavirus in the oral cavity/oropharynx in a large population of children and adolescents. Pediatr Infect Dis J 2007;26:836-840.

24 Pickard RK, Xiao W, Broutian TR, et al. The prevalence and incidence of oral human papillomavirus infection among young men and women, aged 18-30 years. Sex Transm Dis 2012;39:559-566.

25 Sanders AE, Slade GD, Patton LL. National prevalence of oral HPV infection and related risk factors in the US adult population reply. Oral Dis 2012;19:106.

26 Summersgill KF, Smith EM, Levy BT, et al. Human papillomavirus in the oral cavities of children and adolescents. Oral Surg Oral Med Oral Pathol Oral Radiol Endod 2001;91:62-69.

27 Kreimer AR, Pierce Campbell CM, Lin HY, et al. Incidence and clearance of oral human papillomavirus infection in men: the HIM cohort study. Lancet 2013;382:877-887.

28 Beachler DC, Sugar EA, Margolick JB, et al. Risk factors for acquisition and clearance of oral human papillomavirus infection among HIV-infected and HIVuninfected adults. Am J Epidemiol 2014;181:40-53.

29 Beachler DC, Guo Y, Xiao W, et al. High oral human papillomavirus type 16 load predicts long-term persistence in individuals with or at risk for HIV infection. J Infect Dis 2015;212:1588-1591.

30 Chaturvedi AK, Engels EA, Pfeiffer RM, et al. Human papillomavirus and rising oropharyngeal cancer incidence in the United States. J Clin Oncol 2011;29: 4294-4301.

31 Mehanna H, Beech T, Nicholson T, et al. Prevalence of human papillomavirus in oropharyngeal and nonoropharyngeal head and neck cancer-systematic review and meta-analysis of trends by time and region. Head Neck 2013;35:747-755.

32 Attner P, Du J, Nasman A, et al. The role of human papillomavirus in the increased incidence of base of tongue cancer. Int J Cancer 2010;126:2879-2884.

33 Nasman A, Nordfors C, Holzhauser S, et al. Incidence of human papillomavirus positive tonsillar and base of tongue carcinoma: a stabilisation of an epidemic of viral induced carcinoma? Eur J Cancer 2015;51:55-61.

34 Isayeva $\mathrm{T}, \mathrm{Li} \mathrm{Y}$, Maswahu $\mathrm{D}$, et al. Human papillomavirus in non-oropharyngeal head and neck cancers: a systematic literature review. Head Neck Pathol 2012;6 (Suppl 1):S104-S120.

35 Machado J, Reis PP, Zhang T, et al. Low prevalence of human papillomavirus in oral cavity carcinomas. Head Neck Oncol 2010;2:6.

36 Mirghani H, Amen F, Moreau F, et al. Do high-risk human papillomaviruses cause oral cavity squamous cell carcinoma? Oral Oncol 2015;51:229-236.

37 Li J, Mei J, Wang X, et al. Human papillomavirus typespecific prevalence in women with cervical intraepithelial neoplasm in Western China. J Clin Microbiol 2012;50:1079-1081.

38 Cunningham LL Jr., Pagano GM, Li M, et al. Overexpression of p16INK4 is a reliable marker of human papillomavirus-induced oral high-grade squamous dysplasia. Oral Surg Oral Med Oral Pathol Oral Radiol Endod 2006;102:77-81.

39 Angiero F, Gatta LB, Seramondi R, et al. Frequency and role of HPV in the progression of epithelial dysplasia to oral cancer. Anticancer Res 2010;30:3435-3440.

40 McCord C, Xu J, Xu W, et al. Association of high-risk human papillomavirus infection with oral epithelial dysplasia. Oral Surg Oral Med Oral Pathol Oral Radiol 2013;115:541-549.

41 Kratochvil FJ, Cioffi GA, Auclair PL, et al. Virus-associated dysplasia (bowenoid papulosis?) of the oral cavity. Oral Surg Oral Med Oral Pathol 1989;68: 312-316.

42 Daley T, Birek C, Wysocki GP. Oral bowenoid lesions: differential diagnosis and pathogenetic insights. Oral Surg Oral Med Oral Pathol Oral Radiol Endod 2000;90: 466-473.

43 Warnakulasuriya S, Ariyawardana A. Malignant transformation of oral leukoplakia: a systematic review of observational studies. J Oral Pathol Med 2016;45: 155-166.

44 Chaturvedi AK, Engels EA, Anderson WF, et al. Incidence trends for human papillomavirus-related and -unrelated oral squamous cell carcinomas in the United States. J Clin Oncol 2008;26:612-619.

45 Gillison ML, D'Souza G, Westra W, et al. Distinct risk factor profiles for human papillomavirus type 16positive and human papillomavirus type 16-negative 
head and neck cancers. J Natl Cancer Inst 2008;100: 407-420.

46 Klussmann JP, Gultekin E, Weissenborn SJ, et al. Expression of p16 protein identifies a distinct entity of tonsillar carcinomas associated with human papillomavirus. Am J Pathol 2003;162:747-753.

47 Weinberger PM, Yu Z, Kountourakis P, et al. Defining molecular phenotypes of human papillomavirusassociated oropharyngeal squamous cell carcinoma: validation of three-class hypothesis. Otolaryngol Head Neck Surg 2009;141:382-389.

48 Weinberger PM, Yu Z, Haffty BG, et al. Molecular classification identifies a subset of human papillomavirus-associated oropharyngeal cancers with favorable prognosis. J Clin Oncol 2006;24:736-747.

49 Fakhry C, Westra WH, Li S, et al. Improved survival of patients with human papillomavirus-positive head and neck squamous cell carcinoma in a prospective clinical trial. J Natl Cancer Inst 2008;100:261-269.

50 Posner MR, Lorch JH, Goloubeva O, et al. Survival and human papillomavirus in oropharynx cancer in TAX
324: a subset analysis from an international phase III trial. Ann Oncol 2011;22:1071-1077.

51 Ang KK, Sturgis EM. Human papillomavirus as a marker of the natural history and response to therapy of head and neck squamous cell carcinoma. Semin Radiat Oncol 2012;22:128-142.

52 Chaturvedi AK. Epidemiology and clinical aspects of HPV in head and neck cancers. Head Neck Pathol 2012;6(Suppl 1):S16-S24.

53 Nichols AC, Dhaliwal SS, Palma DA, et al. Does HPV type affect outcome in oropharyngeal cancer? J Otolaryngol Head Neck Surg 2013;42:9.

54 Chung CH, Zhang Q, Kong CS, et al. p16 protein expression and human papillomavirus status as prognostic biomarkers of nonoropharyngeal head and neck squamous cell carcinoma. J Clin Oncol 2014;32: 3930-3938.

55 Lassen P, Primdahl H, Johansen J, et al. Impact of HPVassociated p16-expression on radiotherapy outcome in advanced oropharynx and non-oropharynx cancer. Radiother Oncol 2014;113:310-316. 